\title{
Influence of Different Encapsulation Types of Arbuscular Mycorrhizal Fungi on Physiological Adaptation and Growth Promotion of Maize (Zea mays L.) Subjected to Water Deficit
}

\author{
Suravoot YOOYONGWECH ${ }^{1}$, Suriyan CHA-UM ${ }^{2 *}$, Rujira TISARUM ${ }^{2}$, \\ Cattarin THERAWITAYA ${ }^{2}$, Thapanee SAMPHUMPHUNG ${ }^{2}$, Supatida \\ AUMTONG $^{3}$, Jeerun KINGKAEW ${ }^{1}$, Muenduen PHISALAPHONG ${ }^{4}$
}

\author{
${ }^{1}$ Mabidol University, Kanchanaburi Campus, School of Interdisciplinary Studies, Kanchanaburi 71150, \\ Thailand;suravoot@gmail.com; atomic_jee@yahoo.com \\ ${ }^{2}$ National Science and Technology Development Agency (NSTDA), National Center for Genetic Engineering and Biotechnology (BIOTEC), \\ Pathum Thani 12120,Thailand; suriyanc@biotec.or.th (*correspondingauthor); rujira.tis@biotec.or.th; \\ cattarin.the@biotec.or.th; thapanee@biotec.or.th \\ ${ }^{3}$ Maejo University, Faculty of Agricultural Production, Chiang Mai 50290, Thailand; suphathidaaumtong@yahoo.com \\ ${ }^{4}$ Chulalongkorn University, Faculty of Engineering, Department of Chemical Engineering, Bangkok 10330, \\ Thailand; Muenduen.p@chula.ac.th
}

\begin{abstract}
Under drought environment, arbuscular mycorrhizal fungi (AMF) can serve as a long-term biofertilizer to sustain the water and nutrient availability for the host plants. A study was conducted to check the effect of AMF and the encapsulations of the AMF and an organic fertilizer (Fer) with alginate (Al-FA) and agar-agar (Ag-FA) on maize (Zea mays L.) in response to water deficit conditions. The maximum quantum efficiency of PS II $\left(\mathrm{F}_{v} / \mathrm{F}_{m}\right)$ of the maize inoculated with Al-FA and Ag-FA under the water deficit was recorded to be 0.70 and 0.50 , respectively. Shoot and root water content of the Al-FA plants were found to be maintained under the water deficit and were better than Ag-FA. Besides, phosphorus content in the root tissues of the Al-FA plants grown under the water deficit stress was 1.56-folds greater than in the Ag-FA plants, thereby promoting the photosynthetic abilities and plant height in the former case. The study indicated that the Al-FA type of encapsulation may perform better than the Ag-FA in case of maize plants, leading to its better development under water limited conditions.
\end{abstract}

Keywords: arbuscular mycorrhiza; encapsulation; maize; organic fertilizer; water deficit

Abbreviations: Ag-FA: AMF plus Fer coating by agar-agar; AMF: arbuscular mycorrhizal fungi; Al-FA: AMF plus Fer coating by alginate; $\mathrm{F}_{v} / \mathrm{F}_{m}$ : maximum quantum efficiency of PS II; Fer: organic fertilizer

\section{Introduction}

In the scenario of climate change, drought has been reported as one of the major environmental concerns (Wheeler and von Braun, 2013; Coleto et al., 2014; Gauthier et al., 2014; Daryanto et al., 2017). Evidence of water deficit or drought stress are indicated by plant responses such as changes in water uptake, photosynthetic efficiency, and morphological adaptations (Rampino et al., 2006; Suzuki et al., 2014; Rigano et al., 2016). During drought, there is a decrease in the capacity of nutrient uptake due to reduce on uptake rates and fine root biomass (Kreuzwieser and Gessler, 2010).
Microbial assistance in rhizosphere may help to improve the adaptability of crop plants during severe stress conditions (Barea et al., 2005). In case of an association of AMF and plant, the AMF develops into the root cortical cell and participates in the nutrient exchange that is reflected through the enhanced plant productivity (Smith and Read, 2008; Park et al., 2015). On the other hand, AMF inoculation can reduce the water and fertilization requirements and restore leaf hydration under drought, hence making its production more profitable (Ruiz-Lozano, 2003; Mena-Violante et al., 2006). For field applications, use of gel encapsulation procedures for AMF isolated vesicles and internal hyphae or spores are proved to preserve an ability of AMF to regrow hyphae, especially under stressful environment conditions (Plenchette and Strullu, 
214

2003; John et al., 2011; Herrmann and Lesueur, 2013). The encapsulation methods used in practice include thermal gelation, ionic gelation (beads and hallow beads), spray drying and complex coacervation (Vemmer and Patel, 2013). In general, there is no report regarding the comparative efficacy of different encapsulation methods. Only the effects of with or without Na-alginate encapsulated AMF inoculation in the soil has been widely studied (Vassilev et al., 2001; de Jaeger et al., 2011). Furthermore, a part of the encapsulation expected for friendly farmer users and effectively reflected for healthy plants and growth stimulation (Vassilev et al., 2015). By the way, several studies have demonstrated that AMF inoculation acts as long-term fertilizers for maize growth (Toljander et al., 2008; Borriello et al., 2012). Besides, AMF inoculation together with fertilizer application can save an enormous amount of fertilizers apart from increasing the vegetative biomass and yield in wheat (Sharma et al., 2011).

To obtain more information about the AMF applications, the effect of different types of encapsulations of AMF plus organic fertilizer on responses of chlorophyll content and maximum quantum efficiency of PS II $\left(\mathrm{F}_{v} / \mathrm{F}_{m}\right)$, total phosphorus content, free proline content and growth characters of maize grown under water deficit was investigated.

\section{Materials and Methods}

\section{Encapsulated fertilizer materials}

Co-encapsulated beads consisted of AMF and sterilized organic fertilizer (Donk Bua ${ }^{\circ}$ ), were totally used $2.5 \mathrm{~g}$ of the fertilizer and $4 \mathrm{~g}$ of AMF powder (100 spores pot $\left.^{-1}\right)$. The encapsulated beads were coated by calcium alginate (Al-FA) or agar-agar (Ag-FA). In addition, the AMF powder (Micoriza ${ }^{\oplus}, 25$ living spores $\mathrm{g}^{-1}$ of Glomus sp. and Acaulospora sp.) procured from Department of Agriculture, Ministry of Agriculture and Cooperative (Thailand) was used for inoculation as per the method of Yooyongwech et al. (2016).

\section{Plant materials and experimental treatments}

Maize cv. 'Supreme' ('Kreu-ang Bin')) seeds were purchased and germinated in plastic pots containing soil under controlled greenhouse conditions with average temperature of $28.7^{\circ} \mathrm{C}$ and $51.2 \%$ relative humidity (RH). Irrigation was provided with droplet system at a flow rate of $2 \mathrm{~L} \mathrm{~h}^{-1}$ for $5 \mathrm{~min}$ interval time. Plastic pots $(25 \mathrm{~cm}$ in diameter) were prepared using autoclaved soil $\left(2 \mathrm{~kg} \mathrm{pot}^{-1}\right)$ composing of $0.3 \%$ nitrogen, $0.12 \%$ phosphorus, $0.56 \%$ potassium, and $11.19 \%$ organic matter with EC $1.08 \mathrm{dS} \mathrm{m} \mathrm{m}^{-1}$ and $\mathrm{pH}$ 5.58. In the experiment, six treatments were divided and represented by (1) $2.5 \mathrm{~g} \mathrm{pot}^{-1}$ of the organic fertilizer (Fer), (2) $4 \mathrm{~g} \mathrm{pot}^{-1}$ AMF powder (100 spores) (AMF), (3) $2.5 \mathrm{~g} \mathrm{pot}^{-1}$ of the organic fertilizer plus $4 \mathrm{~g} \mathrm{pot}^{-1}$ AMF powder (100 spores) (FA), (4) without AMF and fertilizer (Con). Other two treatments were the encapsulated beads of the (5) Al-FA and (6) the Ag-FA. Well irrigation (WW) was provided at $55.14 \pm 0.52 \%$ soil water content (SWC). For a water deficit (WD) condition, one-month old seedlings of maize were withheld from irrigation (16 days, WD; $34.80 \pm 2.20 \%$ SWC) and then physiological and biochemical changes were recorded.

\section{AMF colonization}

Roots of one-month-old seedlings were collected and stored in $60 \%$ alcohol. In the colonization analysis, the root sample was macerated using $10 \% \mathrm{KOH}$ for $30 \mathrm{~min}$ at $95^{\circ} \mathrm{C}$ and rinsed three times with distilled water. The softened root was incubated in $5 \% \mathrm{HCl}$ for $5 \mathrm{~min}$ and then stained with $0.05 \%$ (weight per volume) tryptan blue for $15 \mathrm{~min}$. The AMF colonization was observed and calculated at $10 \times$ under light microscope (Zeiss, Germany), following the method of Brundrett et al. (1996).

\section{Plant physiological and biochemical analysis}

Total chlorophyll content (TChl) in the second fully expanded leaf from the shoot tip was evaluated by acetone extraction analysis (Shabala et al., 1998). Photosynthesis efficiency or the maximum quantum efficiency of PS II $\left(\mathrm{F}_{v} / \mathrm{F}_{m}\right)$, was measured from the surface of second fully expanded leaf following the method of Yooyongwech et al. (2016).

Phosphorus content in dried leaf and root tissues was measured in terms of blue molybdate-phosphate complexes, read at $420 \mathrm{~nm}$ using spectrophotometer [DR/4000; Model 48000, $\left.\left(\mathrm{HACH}^{\circ}\right)\right]$, according to the method given by Jackson (1958). It was expressed as the relative phosphorus (P) content. Analysis of free proline content in the second fully expanded leaf was done according to Bates et al. (1973) using proline as standard. The reaction mixture was measured by colorimetric method using spectrophotometer [DR/4000; Model 48000, $\left.\left(\mathrm{HACH}^{\circ}\right)\right]$. Osmolarity of leaf tissues was measured as per the method given by Lanfermeijer et al. (1991).

Fresh shoot and root was dried in a hot-air oven at $80^{\circ} \mathrm{C}$ for three days and water content in shoot and root was calculated using the equation: \%Water content $=[(\mathrm{FW}-$ $\mathrm{DW}) \times 100] / \mathrm{FW}$, where FW is fresh weight and DW is dry weight (after oven drying at $70{ }^{\circ} \mathrm{C}$ for $48 \mathrm{~h}$ ).

\section{Statistical analysis}

The experiment consisted of an arrangement of $2 \times 6$ factorial (two types of irrigation conditions and six types of inoculations) in a completely randomized block design with 6 replications. The data were analyzed by analysis of variance (ANOVA) using SPSS software (SPSS ver. 11.5). The means $( \pm \mathrm{SE})$ were compared using Tukey's HSD $(p \leq$ $0.05)$. The physiological and biochemical values were represented by four replications $(n=4)$. AMF-colonization percentage was measured and represented by eight replications $(n=8)$.

\section{Results}

\section{AMF root colonization}

Root colonization in the AMF-inoculated seedlings (mycorrhizal treated-plants by FA, AMF, Al-FA, and AgFA) was evidently detected ( $>70 \%$ colonization). In the organic fertilizer (Fer), AMF root colonization was observed, whereas it was absent in the control seedlings. Colonization percentages in the Al-FA and Ag-FA encapsulated treated-plants under well-watered condition were $74.16 \%$ and $79.60 \%$, respectively (Fig. 1). 


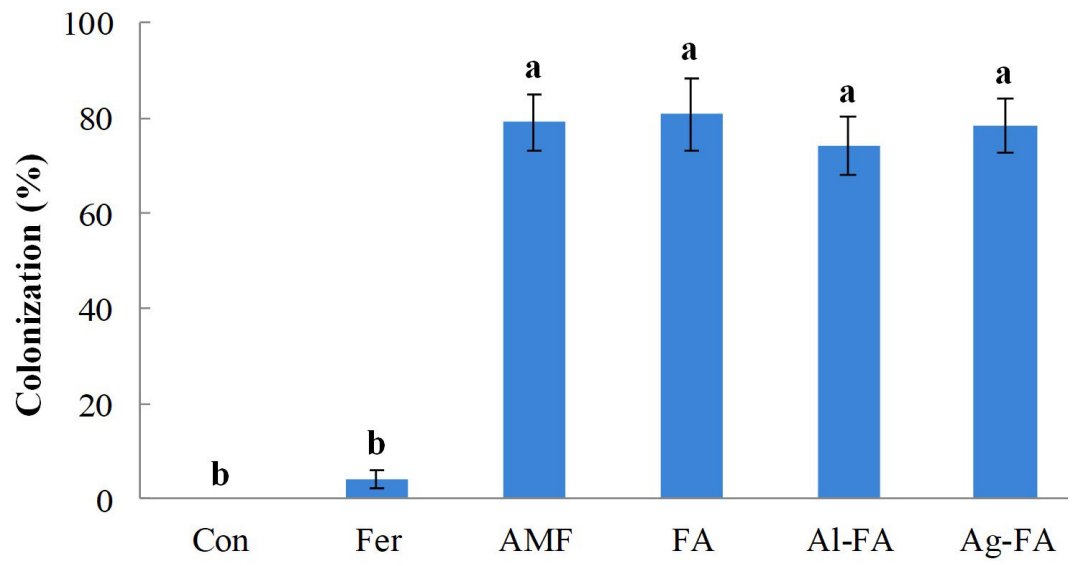

Fig. 1. Root colonization in control (Con), organic fertilizer (Fer), inoculated conditions of arbuscular mycorrhiza (AMF), organic fertilizer plus AMF (FA), FA encapsulated alginate (Al-FA), and FA encapsulated agar (Ag-FA). Mean values ( \pm SE) with the letter are significant different at $p \leq 0.05$

\section{Phosphorus content in maize under water deficit}

Total phosphorus content in the leaf tissues of maize seedlings grown under well-watered conditions was unchanged when compared with controlled seedlings, except in the organic fertilizer-treated seedlings (Fer), where it showed an increasing trend (Fig. 2).

In water deficit, the $\mathrm{P}$ content in the leaf tissues was decreased in the Fer treatment $(76.3 \%$ reduction compared to corresponding WW condition), AMF (63.3\% reduction compared to corresponding WW condition) and control (46.0\% reduction compared to corresponding WW condition). Interestingly, the P content in FA, Al-FA and Ag-FA was maintained when seedlings were subjected to water deficit conditions (Fig. 2). The P content in the root tissues of the AMF, FA and Al-FA treated seedlings grown under WW conditions were greater than the control seedlings. Under water deficiency, the P content in control seedlings declined by $47 \%$ over corresponding WW condition. In addition, the P content in all AMF treatments (AMF, FA, Al-FA and Ag-FA) under water deficit stress was maintained when compared with control (Fig. 2).

\section{Physiology and growth parameters under water deficit}

Free proline content in the leaf tissues of maize seedlings grown under WW was similar for all the treatments except for the Al-FA treated seedlings which had slightly lower content than all the other treatments $\left(17.49 \mu \mathrm{mol} \mathrm{g} \mathrm{FW}^{-1}\right)$. In the WD, the free proline level in the Al-FA plant was unchanged compared to other treatments. In the control plants, the maximum free proline content was observed to be $24.75 \mu \mathrm{mol} \mathrm{g}^{-1} \mathrm{FW}$ under well irrigated conditions (Fig. 3). Consequently, free proline enrichment in the controlled seedlings under the WD play a major role in osmotic adjustment to control the leaf osmotic potential. In the WD, the osmotic potential in the leaf tissues of control seedlings was sharply declined by $39.9 \%$ over WW seedlings, whereas the value of the Al-FA seedlings was closely maintained in the AMF-treated seedlings (Table 1). Shoot and root relative water content in AMF treated seedlings under the WD were maintained (Fig. 4). In control seedlings, shoot and root relative water content declined by $4.8 \%$ and $10.6 \%$, respectively, when plants were exposed to the WD. Similar trend was observed in Fer treatment, where the free proline content was significantly dropped in the plant grown under the WD.

TChl in the leaf tissues of Fer and AMF inoculated seedlings was maintained when exposed to water deficit conditions. Interestingly, TChl content in control seedlings under the WD was reduced by $31.3 \%$ than in the WW seedlings (Table 2).

Maximum quantum efficiency of PS II $\left(\mathrm{F}_{v} / \mathrm{F}_{m}\right)$, a sensitive chlorophyll fluorescence parameter in plants treated with the Fer, AMF, FA, and Al-FA under the WD was maintained, leading to retained plant growth, as represented by plant height (Table 2). In contrast, the $\mathrm{F}_{v} / \mathrm{F}_{m}$ in Ag-FA treated seedlings under the WD was significantly declined by $27.5 \%$ over the WW seedlings (Table 2). In addition, plant height of Ag-FA treated seedlings was evidently retarded in both with or without irrigation conditions.

Table 1. Leaf osmotic potential in control (Con), organic fertilizer (Fer), inoculated conditions of arbuscular mycorrhiza (AMF), organic fertilizer plus AMF (FA), FA encapsulated alginate (Al-FA), and FA encapsulated agar (Ag-FA) subsequently grown under well-watering (WW) or waterdeficit (WD) conditions

\begin{tabular}{|c|c|c|c|}
\hline \multirow{2}{*}{ Treatment } & \multicolumn{2}{|c|}{ Osmotic potential $(\mathrm{MPa})$} & \multirow{2}{*}{ Osmotic potential WDc-AMF (MPa) } \\
\hline & WW & WD & \\
\hline Con & $-0.814 \pm 0.06^{a}$ & $-1.139 \pm 0.08^{\mathrm{b}}(28.71 \%)$ & -0.061 \\
\hline Fer & $-1.086 \pm 0.05^{b}$ & $-1.214 \pm 0.09^{\mathrm{b}}(10.54 \%)$ & -0.136 \\
\hline AMF & $-1.193 \pm 0.17^{\mathrm{b}}$ & $-1.078 \pm 0.07^{\mathrm{b}}(0 \%)$ & 0 \\
\hline FA & $-0.938 \pm 0.15^{b}$ & $-1.133 \pm 0.19^{\mathrm{b}}(17.21 \%)$ & -0.054 \\
\hline Al-FA & $-1.189 \pm 0.10^{\mathrm{b}}$ & $-1.100 \pm 0.08^{\mathrm{b}}(0 \%)$ & -0.022 \\
\hline $\mathrm{Ag}-\mathrm{FA}$ & $-1.207 \pm 0.11^{\mathrm{b}}$ & $-1.136 \pm 0.08^{\mathrm{b}}(0 \%)$ & -0.058 \\
\hline
\end{tabular}

Mean values $( \pm \mathrm{SE})$ with the letter are significant different at $p \leq 0.05$.

The osmotic potential wD-cAMF is determined to compare the osmotic potential under water-deficit condition of AMF plants with other treatments (Con, Fer, FA, Al$\mathrm{FA}$, and Ag-FA) by osmotic potential WD of interests - osmotic potential WD of AMF. The value in parenthesis represents the \% reduction between WD and WW conditions 
Table 2. Total chlorophyll content (TChl), maximum quantum efficiency of PS II $\left(F_{v} / F_{m}\right)$ and plant height in control (Con), organic fertilizer (Fer), inoculated conditions of arbuscular mycorrhiza (AMF), organic fertilizer plus AMF (FA), FA encapsulated alginate (Al-FA), and FA encapsulated agar (Ag-FA) subsequently grown under well-watering (WW) or water-deficit (WD) conditions

\begin{tabular}{|c|c|c|c|c|c|c|}
\hline \multirow{2}{*}{ Treatment } & \multicolumn{2}{|c|}{ TChl $\left(\mu \mathrm{g} \mathrm{g}^{-1} \mathrm{FW}\right)$} & \multicolumn{2}{|c|}{$\overline{\mathrm{F}_{v} / \mathrm{F}_{m}}$} & \multicolumn{2}{|c|}{ Plant height $(\mathrm{cm})$} \\
\hline & WW & WD & WW & WD & WW & WD \\
\hline Con & $14.4 \pm 1.2^{\mathrm{a}}$ & $\begin{array}{l}9.9 \pm 0.6^{b} \\
(31.25 \%)\end{array}$ & $0.69 \pm 0.009^{a}$ & $\begin{array}{c}0.66 \pm 0.005^{a} \\
(4.35 \%)\end{array}$ & $111.1 \pm 5.9^{\mathrm{ab}}$ & $108.2 \pm 3.6^{\mathrm{ab}}(2.61 \%)$ \\
\hline Fer & $16.4 \pm 1.6^{a}$ & $\begin{array}{l}13.8 \pm 1.9^{\mathrm{ab}} \\
(15.85 \%)\end{array}$ & $0.73 \pm 0.001^{a}$ & $\begin{array}{c}0.72 \pm 0.003^{\mathrm{a}} \\
(1.37 \%)\end{array}$ & $110.2 \pm 5.4^{\mathrm{ab}}$ & $112.3 \pm 4.4^{\mathrm{ab}}(0 \%)$ \\
\hline AMF & $14.4 \pm 1.0^{\mathrm{a}}$ & $\begin{array}{l}12.8 \pm 1.5^{\mathrm{ab}} \\
(11.11 \%)\end{array}$ & $0.70 \pm 0.004^{\mathrm{a}}$ & $\begin{array}{c}0.69 \pm 0.011^{\mathrm{a}} \\
(1.43 \%)\end{array}$ & $114.0 \pm 3.4^{\mathrm{ab}}$ & $116.8 \pm 4.0^{\mathrm{a}}(0 \%)$ \\
\hline FA & $17.3 \pm 1.5^{\mathrm{a}}$ & $\begin{array}{l}12.7 \pm 0.1^{\mathrm{ab}} \\
(26.59 \%)\end{array}$ & $0.73 \pm 0.014^{a}$ & $\begin{array}{c}0.70 \pm 0.009^{\mathrm{a}} \\
\quad(4.11 \%)\end{array}$ & $112.1 \pm 6.0^{\mathrm{ab}}$ & $111.0 \pm 4.5^{\mathrm{ab}}(1.00 \%)$ \\
\hline $\mathrm{Al}-\mathrm{FA}$ & $17.6 \pm 1.8^{a}$ & $\begin{array}{c}12.1 \pm 0.6^{\mathrm{ab}} \\
(31.25 \%)\end{array}$ & $0.72 \pm 0.007^{a}$ & $\begin{array}{c}0.70 \pm 0.009^{\mathrm{a}} \\
(2.78 \%)\end{array}$ & $103.9 \pm 4.1^{\mathrm{ab}}$ & $110.1 \pm 3.2^{\mathrm{ab}}(0 \%)$ \\
\hline $\mathrm{Ag}-\mathrm{FA}$ & $11.9 \pm 0.3^{\mathrm{ab}}$ & $\begin{array}{c}10.8 \pm 1.7^{\mathrm{ab}} \\
(9.24 \%)\end{array}$ & $0.69 \pm 0.010^{\mathrm{a}}$ & $\begin{array}{c}0.50 \pm 0.080^{\mathrm{b}} \\
(27.54 \%)\end{array}$ & $99.2 \pm 2.5^{\mathrm{b}}$ & $95.3 \pm 3.8^{\mathrm{b}}(3.93 \%)$ \\
\hline
\end{tabular}

Mean values $( \pm$ SE) with the letter are significant different at $p \leq 0.05$.

The value in parenthesis represents the \% reduction between WD and WW conditions
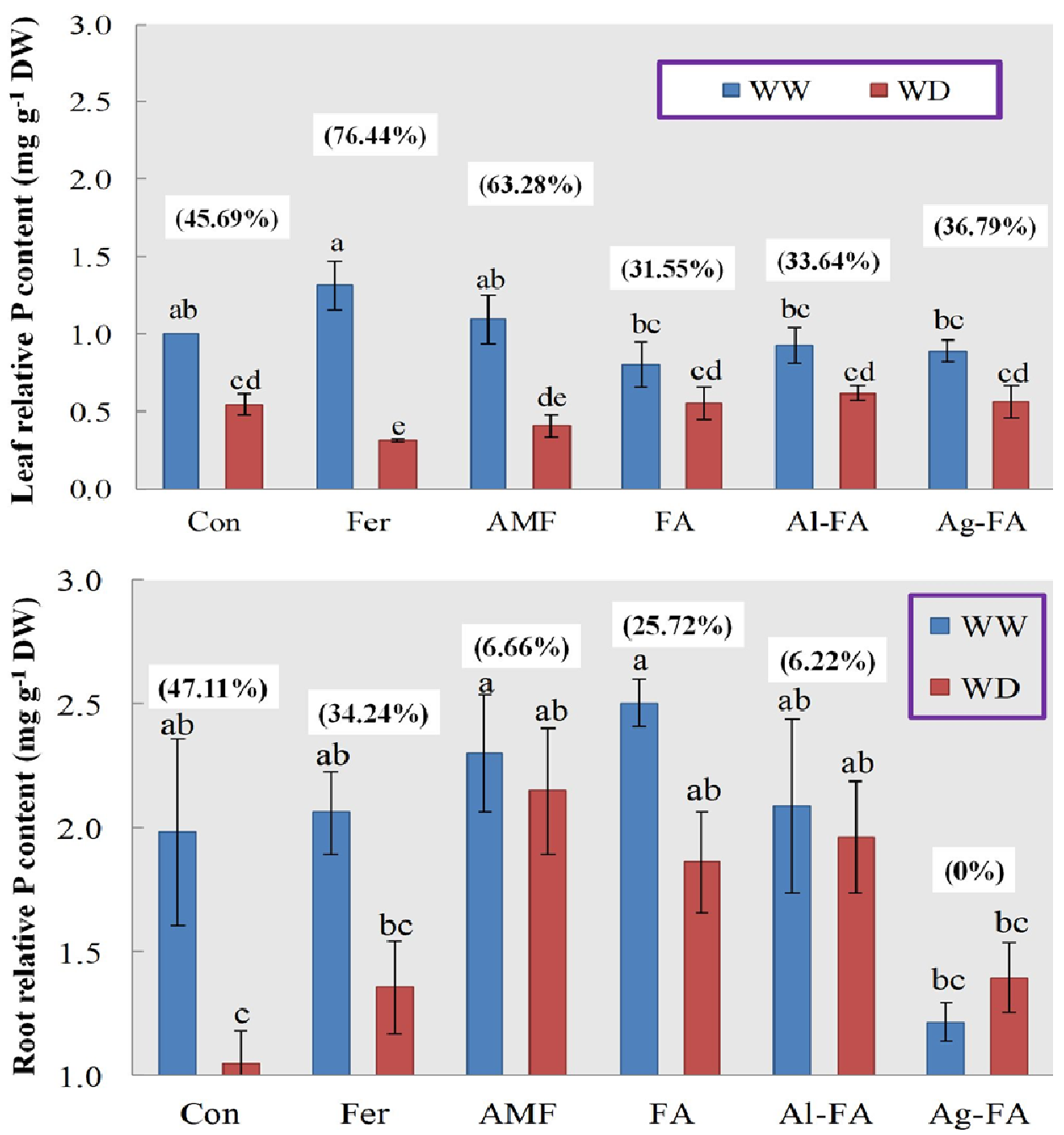

(A)

(B)

Fig. 2. Relative phosphorus content in leaf (A) and root tissues (B) of control (Con), organic fertilizer (Fer), inoculated conditions of arbuscular mycorrhiza (AMF), organic fertilizer plus AMF (FA), FA encapsulated alginate (Al-FA), and FA encapsulated agar (Ag-FA) subsequently grown under well-watering (WW) or water deficit (WD) conditions. Mean values ( \pm $\mathrm{SE}$ ) with the letter are significant different at $p \leq 0.05$. The value in parenthesis represents the $\%$ reduction between WD and WW conditions 


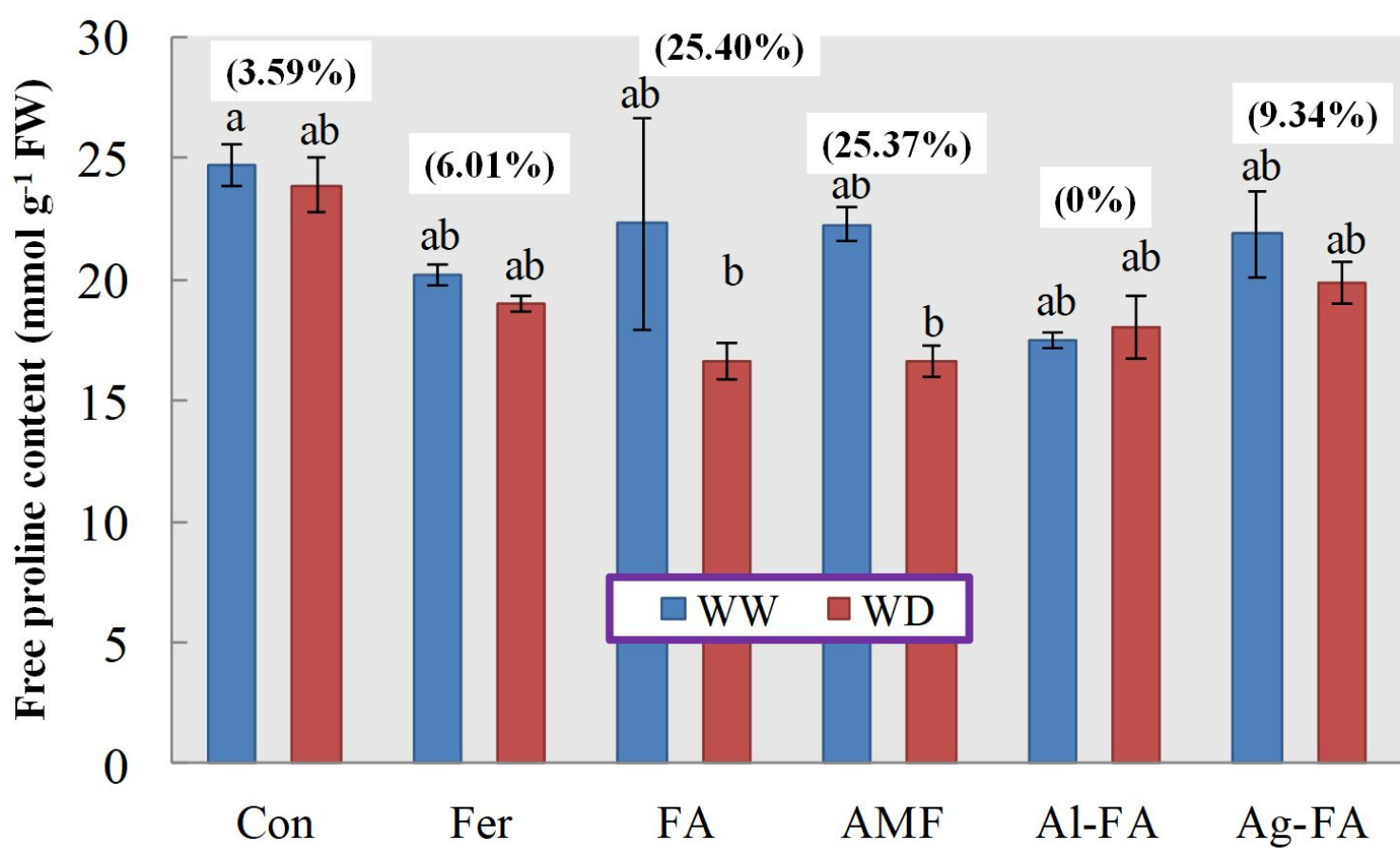

Fig. 3. Free proline content in leaf tissues of control (Con), organic fertilizer (Fer), inoculated conditions of arbuscular mycorrhiza (AMF), organic fertilizer plus AMF (FA), FA encapsulated alginate (Al-FA), and FA encapsulated agar (Ag-FA) subsequently grown under well-watering (WW) or water deficit (WD) conditions. Mean values $( \pm$ SE) with the letter are significant different at $p \leq 0.05$. The value in parenthesis represents the $\%$ reduction between WD and WW conditions

\section{Discussion}

Under water deficit, the inoculation of the Al-FA encapsulation type seemed to maintain the chlorophyll content and the $\mathrm{F}_{v} / \mathrm{F}_{m}$ in the maize plants, as same as the FA, and AMF plants, indicating that the mycorrhiza in the encapsulation type may able to be involved the photosynthetic system and more effective in these plants. Mirshad and Puthur (2016) supported that reduction in the chlorophyll content was high in non-AMF plants under drought conditions, which might be due to the suppression of enzymes involved in process of chlorophyll biosynthesis. Some reports of drought stress mentioned that AMF symbiosis assisted in reducing the chlorophyll loss and positively affected the photochemistry of PSII in watermelon (Mo et al., 2016). In agreement with the previous observations of Yooyongwech et al. (2016), photosynthesis efficiency in the present study was enhanced upon AMF application in the target plant under water deficit stress. A decrease in the expression of $P A O$ and $P P H$, the key genes in chlorophyll-breakdown process in noninoculated plants, and an increase in the expression of $R B C S$ and $R B C L$ genes involved in initial Rubisco activity have been observed under water deficit conditions upon AMFinoculation (Mo et al., 2016). The chlorophyll content and photosynthesis efficiency, $F_{v} / F_{m}$, relative to the control, were also improved under the water deficit, even treating the plants with fertilizer alone. Previous studies have also reported that the fertilized plants had improved chlorophyll content compared to the non-fertilized plants (Fan et al., 2014).
However, low water availability and total P content in both shoot and root of the Fer treated plants may imply that the fertilizer alone may not be beneficial enough to maintain plants under the WD. Whereas, in case of the AMF-related plants (Al-FA, FA, and AMF), these parameters were successfully maintained. Sajedi et al. (2010) supported the view that AMF enhanced the water efficiency in maize plants subjected to drought conditions. This could be due to an activated extraradical mycelium (ERM) of AMF in the soil as reported by Derelle et al. (2012), Zouet al. (2015). The ERM are hydrophilic in nature and arrange water in the rhizosphere of the host plants across mycelium tips, even during drought conditions (Derelle et al., 2012; Zou et al., 2015). Particularly, the interaction of AMF mycelium or hyphae in host plants (symbiont) might be helpful in retaining the water availability in the soil as well as in contributing phosphorus as macronutrient for plant growth and development (Neumann et al., 2009; Hodge et al., 2010).

In the same way, free proline content in case of Al-FA FA, and the AMF treated plants under the WD condition was comparatively low unlike in non-mycorrhizal plants (Con and Fer), and Ag-FA treated plants. Under drought conditions, the lower levels of free proline content in AMF treated Populus spp. were observed (Liu et al., 2016). Proline is known to play a key role in plant osmoregulation (Jinyou et al., 2004; Hayat et al., 2012) and the lower accumulation of free proline was performed to maintain osmotic pressure in the AMF plants to avoid drought stress (Porcel and RuizLozano, 2004; Liu et al., 2016). In addition, the calcium 

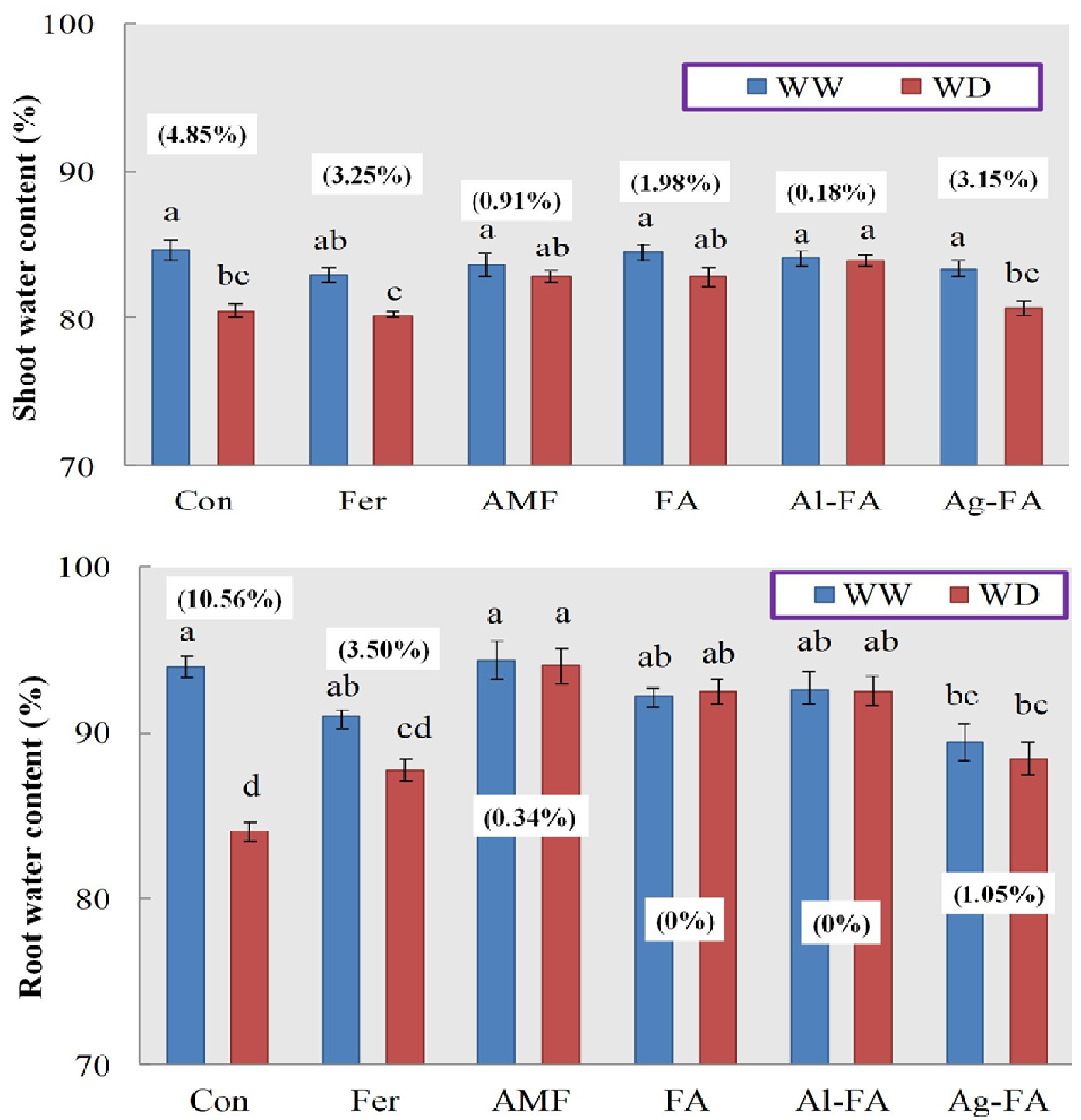

Fig. 4. Water content in shoot (A) and root tissues (B) of control (Con), organic fertilizer (Fer), inoculated conditions of arbuscular mycorrhiza (AMF), organic fertilizer plus AMF (FA), FA encapsulated alginate (Al-FA), and FA encapsulated agar (Ag-FA) subsequently grown under well-watering (WW) or water deficit (WD) conditions. Mean values $( \pm$ SE) with the letter are significant different at $p \leq 0.05$. The value in parenthesis represents the $\%$ reduction between WD and WW conditions

compound of alginate coating agent in the Al-FA treatment may regulate the free proline accumulation in the treated plants under the two irrigated conditions that caused decrease in free proline content in Al-FA treated plants, even under the WW. Xu et al. (2013) proved that external application of the low doses of calcium chloride (5-10 mM) induced a reduction of proline content in Zoysia grass, especially under drought. Moreover, calcium is one of the important plant-nutrients and it acts as a secondary messenger in the cellular signaling pathways, participates in $\mathrm{H}_{2} \mathrm{O}_{2}$ perception and induces antioxidant genes (Rentel and Knight, 2004; Tuteja and Mahajan, 2007) in regard to drought avoidance and plant water use efficiency (Shao $e t$ al., 2008).

In the Ag-FA plants, the water and $\mathrm{P}$ content appeared relatively lower than in Al-FA plant, despite the high percentage of root colonization in both the treatments. In the roots, the trend of water and P content was evidently decreasing under both WW and WD (Fig. 2). This lower level of the water and P content may be due to the film segments of agar that were dried under water dehydration and turned thick when exposed to open conditions (Rigou et al., 1995). It could also be possible that a portion of coated agar-agar film on the beads interfered the water movement through the external hyphae of mycorrhiza and/or root from the rhizosphere, leading to decrease in the efficiency of water adsorption and nutrient fixation. Besides, the reduction in water use efficiency directly affected the quantum efficiency of PSII in the plant cell (Ren et al., 2015). This caused gradual reduction in the photosynthetic efficiency and plant height in case of Ag-FA treated plants (Table 2). Eventually, an encapsulated agar-agar film of the Ag-FA inhibits the maize growth and development under the WW and the WD conditions. It also depends on the softening coat beads, drying period and the type of microorganism (Vemmer and Patel, 2013). 


\section{Conclusions}

The two types of encapsulations of the AMF and the organic fertilizer with the calcium-alginate (Al-FA) and the agar-agar (Ag-FA) responded differently on the maize plants. The plants treated with the Al-FA beads allowed the maintenance of maximum quantum efficiency of PS II $\left(F_{v} / F_{m}\right)$, chlorophyll content, water content in shoot and root, and phosphorus content, especially in the root parts under the water deficit condition. In the water deficit, free proline content of the Al-FA treated plants remained low. Water availability and total phosphorus in the Ag-FA plant under WW and WD conditions were limited, leading to inhibited photosynthetic efficiency and growth performances. According to the results, Al-FA proved more reliable in alleviating the water deficit stress in maize. The Al-FA beads may provide an option for further research, development and practical applications for the improvement of maize growth under drought.

\section{Acknowledgements}

This study was a part of research project on improving AMF-biofertilizer for crop requirements. The authors would like to thank The Thailand Research Fund (TRF) for supporting the work (grant No. SRI5920201).

\section{References}

Barea JM, Pozo MJ, Azcón R, Azcón-Aguilar C (2005). Microbial cooperation in rhizosphere. Journal of Experimental Botany 56:1761-1778.

Bates LS, Waldren RP, Teare ID (1973). Rapid determination of free proline for water-stress studies. Plant and Soil 39:205-207.

Borriello R, Lumini E, Girlanda M, Bonfante P, Bianciotto V (2012). Effects of different management practices on arbuscular mycorrhizal fungal diversity in maize fields by a molecular approach. Biology and Fertility Soil 48:911-922.

Brundrett MC, Bougher N, Dell B, Grove T, Malajczuk N (1996). Working with mycorrhizas in forestry and agriculture (ACIAR Monograph 32). Australian Centre for International Agricultural Research, Canberra.

Coleto I, Pineda M, Rodiño AP, De Ron AM, Alamillo JM (2014). Comparison of inhibition of $\mathrm{N}_{2}$ fixation and ureide accumulation under water deficit in four common bean genotypes of contrasting drought tolerance. Annals of Botany 113:1071-1082.

Daryanto S, Wang L, Jacinthe PA (2017). Global synthesis of drought effects on cereal, legume, tuber and root crops production: A review. Agricultural Water Management 179:18-33.

de Jaeger N, de la Providencia IE, Rouhier H, Declerck S (2011). Coentrapment of Trichoderma harzianum and Glomus sp. within alginate beads: Impact on the arbuscular mycorrhizal fungi life cycle. Journal of Applied Microbiology 111:125-135.

Derelle D, Declerck S, Genet P, Dajoz I, van Aarle IM (2012). Association of highly and weakly mycorrhizal seedlings can promote the extra- and intra-radical development of a common mycorrhizal network. FEMS Microbiology Ecology 79:251-259.
Fan HM, Wang XW, Sun X, Li YY, Sun XZ, Zheng CS (2014). Effects of humic acid derived from sediments on growth, photosynthesis and chloroplast ultrastructure in chrysanthemum. Scientia Horticulturae 177:118-123.

Gauthier PPG, Crous KY, Ayub G, Duan H, Weerashinghe LK, Ellsworth DS, ... Atkin OK (2014). Drought increase heat tolerance of leaf respiration in Eucalyptus globulus saplings grown under both ambient and elevated atmospheric $\left[\mathrm{CO}_{2}\right]$ and temperature. Journal of Experimental Botany 65:6471-6485.

Hayat S, Hayat Q, Alyemeni MN, Wani AS, Pichtel J, Ahmad A (2012). Role of proline under changing environments. Plant Signaling \& Behavior 7:1456-1466.

Herrmann L, Lesueur D (2013). Challenges of formulation and quality of biofertilizers for successful inoculation. Applied Microbiology and Biotechnology 97:8859-8873.

Hodge A, Helgason T, Fitter AH (2010). Nutritional ecology of arbuscular mycorrhizal fungi. Fungal Ecology 3:267-273.

Jackson ML (1958). Soil Chemical Analysis. Prentice Hall, Englewood Cliffs, New Jersey.

Jinyou D, Xiaoyang C, Wei L, Qiong G (2004). Osmoregulation mechanism of drought stress and genetic engineering strategies for improving drought resistance in plants. Forest Studies in China 6:56-62.

John RP, Tyagi RD, Brar SK, Surampalli RY, Prévost D (2011).Bioencapsulation of microbial cells for targeted agricultural delivery. Critical Reviews in Biotechnology 31:211-226.

Kreuzwieser J, Gessler A (2010). Global climate change and tree nutrition: Influence of water availability. Tree Physiology 30:12211234.

Lanfermeijer FC, Koerselman-Kooij JW, Borstlap AC (1991). Osmosensitivity of sucrose uptake by immature pea cotyledons disappears during development. Plant Physiology 95:832-838.

Liu T, Li Z, Hui C, Tang M, Zhang H (2016). Effect of Rhizophagus irregularis on osmotic adjustment, antioxidation and aquaporin PIP genes expression of Populus $\times$ canadensis 'Neva' under drought stress. Acta Physiologiae Plantarum 38:191.

Mena-Violante HG, Ocampo-Jiménez O, Dendooven L, MartínezSoto G, González-Castañeda J, Davies, FT Jr, Olalde-Portugal V (2006). Arbuscular mycorrhizal fungi enhance fruit growth and quality of chile ancho (Capsicum annuum L. cr. San Luis) plants exposed to drought. Mycorrhiza 16:261-267.

Mirshad PP, Puthur JT (2016). Arbuscular mycorrhizal association enhances drought tolerance potential of promising bioenergy grass (Saccharum arundinaceum Retz.). Environmental Monitoring and Assessment 188:425.

Mo Y, Wang Y, Yang R, Zheng J, Liu C, Li H, Ma J, Zhang Y, Wei C, Zhang X (2016). Regulation of plant growth, photosynthesis, antioxidation and osmosis by an arbuscular mycorrhizal fungus in watermelon seedlings under well-watered and drought conditions. Frontiers in Plant Science 7:644.

Neumann E, Schmid B, Römheld V, George E (2009). Extraradical development and contribution to plant performance of an arbuscular mycorrhizal symbiosis exposed to complete or partial root zone drying. Mycorrhiza 20:13-23. 
220

Park HJ, Floss DS, Levesque-Tremblay V, Bravo A, Harrison MJ (2015). Hyphal branching during arbuscule development requires reduced arbuscular mycorrhiza. Plant Physiology 169:2774-2788.

Plenchette C, Strullu DG (2003). Long-term viability and infectivity of intraradical forms of Glomus intraradices vesicles encapsulated in alginate beads. Mycological Research 107:614-616.

Porcel R, Ruiz-Lozano JM (2004). Arbuscular mycorrhizal influence on leaf water potential, solute accumulation, and oxidative stress in soybean plants subjected to drought stress. Journal of Experimental Botany 55:1743-1750.

Rampino P, Pataleo S, Gerardi C, Mita G, Perrotta C (2006). Drought stress response in wheat: physiological and molecular analysis of resistant and sensitive genotypes. Plant, Cell \& Environment 29:2143-2152.

Ren B, Wang M, Chen Y, Sun G, Li Y, Shen Q, Guo S (2015). Water absorption is affected by the nitrogen supply to rice plants. Plant and Soil 396:397-410.

Rentel MC, Knight MR (2004). Oxidative stress-induced calcium signaling in Arabidopsis. Plant Physiology 135:1471-1479.

Rigano MM, Arena C, Di Matteo A, Sellitto S, Frusciante L, Barone A (2016). Eco-physiological response to water stress of droughttolerant and drought-sensitive tomato genotypes. Plant Biosystems 150:682-691.

Rigou L, Mignard E, Plassard C, Arvieu JC, Remy JC (1995). Influence of ectomycorrhizal infection on the rhizosphere $\mathrm{pH}$ around roots of maritime pine (Pinus pinaster Soland in Ait.). New Phytologist 130:141-147.

Ruiz-Lozano JM (2003). Arbuscular mycorrhizal symbiosis and alleviation of osmotic stress: new perspectives for molecular studies. Mycorrhiza 13:309-317.

Sajedi NA, Ardakani MR, Rejali F, Mohabbati F, Miransari M (2010).Yield and yield components of hybrid corn (Zea mays L.) as affected by mycorrhizal symbiosis and zinc sulfate under drought stress. Physiology and Molecular Biology of Plants 16:343-351.

Shabala SN, Shabala SI, Martynenko AI, Babourina O, Newman IA (1998). Salinity effect on bioelectric activity growth, $\mathrm{Na}^{+}$ accumulation and chlorophyll fluorescence of maize leaves: a comparative survey and prospects for screening. Australian Journal of Plant Physiology 25:609-616.

Sharma MP, Reddy UG, Adholeya A (2011). Response of arbuscular mycorrhizal fungi on wheat (Triticum aestivum L.) grown conventionally and on beds in a sandy loam soil. Indian Journal of Microbiology 51(3):384-389.
Shao HB, Song WY, Chu LY (2008). Advances of calcium signals involved in plant anti-drought. Comptes Rendus Biologies331:587596.

Smith SE, Read DJ (2008). Mycorrhizal symbiosis ( $3^{\text {rd }}$ ed). Academic Press, Amsterdam; Boston.

Suzuki N, Rivero RM, Shulaev V, Blumwald E, Mittler R (2014). Abiotic and biotic stress combinations. New Phytologist 203:32-43.

Toljander JF, Santos-González JC, Tehler A, Finlay RD (2008). Community analysis of arbuscular mycorrhizal fungi and bacteria in the maize mycorrhizosphere in a longterm fertilization trial. FEMS Microbiology Ecology 65:323-338.

Tuteja N, Mahajan S (2007). Calcium signalling network in plants: An overview. Plant Signaling \& Behavior 2:79-85.

Vassilev N, Vassileva M, Azcon R, Medina A (2001). Interactions of an arbuscular mycorrhizal fungus with free or co-encapsulated cells of Rhizobium trifoli and Yarowia lipolytica inoculated into a soil-plant system. Biotechnology Letters 23:149-151.

Vassilev N, Vassileva M, Lopez A, Martos V, Reyes A, Maksimovic I, Eichler-Löbermann B, Malusà E (2015). Unexploited potential of some biotechnological techniques for biofertilizer production and formulation. Applied Microbiology and Biotechnology 99:49834996.

Vemmer M, Patel AV (2013). Review of encapsulation methods suitable for microbial biological agents. Biological Control 67:380389.

Wheeler T, von Braun J (2013). Climate change impacts on global food security. Science 341:508-513.

Xu C, Li X, Zhang L (2013). The effect of calcium chloride on growth, photosynthesis, and antioxidant responses of Zoysia japonica under drought conditions. PLoS One 8:e68214.

Yooyongwech S, Samphumphuang T, Tisarum R, Theerawitaya C, Cha-um $S$ (2016). Arbuscular mycorrhizal fungi (AMF) improved water deficit tolerance in two different sweet potato genotypes involves osmotic adjustments via soluble sugar and free proline. Scientia Horticulturae 198:107-117.

Zou YN, Srivastava AK, Ni QD, Wu QS (2015). Disruption of mycorrhizal extraradical mycelium and changes in leaf water status and soil aggregate stability in root box-grown trifoliate orange. Frontiers in Microbiology 6:203. 